\title{
Incidence of tuberculosis among school- going adolescents in South India
}

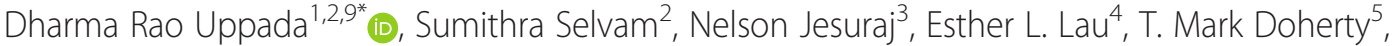 \\ Harleen M. S. Grewal ${ }^{6,7}$, Mario Vaz ${ }^{2,8}$, Bernt Lindtjørn ${ }^{9}$ and TB Trials Study Group
}

\begin{abstract}
Background: Tuberculosis (TB) incidence data in vaccine target populations, particularly adolescents, are important for designing and powering vaccine clinical trials. Little is known about the incidence of tuberculosis among adolescents in India. The objective of current study is to estimate the incidence of pulmonary tuberculosis (PTB) disease among adolescents attending school in South India using two different surveillance methods (active and passive) and to compare the incidence between the two groups.

Methods: The study was a prospective cohort study with a 2-year follow-up period. The study was conducted in Palamaner, Chittoor District of Andhra Pradesh, South India from February 2007 to July 2010. A random sampling procedure was used to select a subset of schools to enable approximately 8000 subjects to be available for randomization in the study. A stratified randomization procedure was used to assign the selected schools to either active or passive surveillance. Participants who met the criteria for being exposed to TB were referred to the diagnostic ward for pulmonary tuberculosis confirmation. A total number of 3441 males and 3202 females between the ages 11 and less than 18 years were enrolled into the study.

Results: Of the 3102 participants in the active surveillance group, four subjects were diagnosed with definite tuberculosis, four subjects with probable tuberculosis, and 71 subjects had non-tuberculous Mycobacteria (NTM) isolated from their sputum. Of the 3541 participants in the passive surveillance group, four subjects were diagnosed with definite tuberculosis, two subjects with probable tuberculosis, and 48 subjects had non-tuberculosis Mycobacteria isolated from their sputum. The incidence of definite + probable TB was 147.60 / 100,000 person years in the active surveillance group and 87 / 100,000 person years in the passive surveillance group.

Conclusion: The incidence of pulmonary tuberculosis among adolescents in our study is lower than similar studies conducted in South Africa and Eastern Uganda - countries with a higher incidence of tuberculosis and human immunodeficiency virus (HIV) than India. The study data will inform sample design for vaccine efficacy trials among adolescents in India.
\end{abstract}

Keywords: Pulmonary tuberculosis, TB incidence, Adolescents, South India, TB vaccine trials

\section{Background}

The incidence of tuberculosis (TB) has declined globally from 139 per 100,000 person years in 2005 to 126 per 100,000 person years in 2013. During the same period, the overall incidence in India declined from 209 to 171 per 100,000 person years [1]. Even so, TB accounts for

\footnotetext{
* Correspondence: druppadajan13@gmail.com

'Department of Pharmacology, Rangaraya Medical College, Kakinada, Andhra Pradesh 533001, India

${ }^{2}$ St. John's Research Institute, Bangalore, India

Full list of author information is available at the end of the article
}

approximately one million deaths every year globally, according to a recent WHO report, of which 0.24 million deaths were in India. India alone accounts for approximately $24 \%$ of all incident TB cases globally [1]. One of the most effective strategies for the control of tuberculosis is mass vaccination with an effective TB vaccine [2-4]. The Bacillus Calmette-Guérin (BCG) vaccine has been recommended at birth in high burden countries based on its efficacy in reducing TB disease in children, although efficacy wanes with time [5, 6]. Given that exposure to tuberculosis increases with age in high burden 
countries and that there is an increase in the incidence of TB disease in early adulthood, there is a need for the development of a pre-exposure and/or a post-exposure $\mathrm{TB}$ vaccine that could be administered to adolescents prior to adulthood.

TB incidence data in vaccine target populations are important for the design of late-phase vaccine clinical trials. Little is known about the incidence of TB in adolescents in India, although it has been reported that the risk of acquiring TB disease after TB infection is higher in adolescents compared to adults [7]. Based on the agestratified data available, the new smear positive case notification in 2011 of individuals between 15 and 24 years in India was approximately 0.13 million, which was $20.56 \%$ of total smear positive cases among all age groups in India [8].

The reported incidence of TB disease may be affected by how it was detected. It is possible that in active surveillance (periodic home visits), the disease is picked up at an earlier stage by sputum culture (sputum collected through either gastric lavage or induced sputum) even though the participant might not have symptoms suggestive of tuberculosis. In passive surveillance (where participants self-report for a diagnostic evaluation), it is more likely for TB to be diagnosed at a later stage when symptoms suggestive of tuberculosis are present. While there are obvious advantages to active surveillance, costs and manpower are considerably higher. Therefore, the present methodology was used to determine whether less expensive passive surveillance would yield similar estimates of TB incidence compared to active surveillance. The results would have implications in the study design of large field studies that test new $\mathrm{TB}$ vaccine efficacy.

\section{Objective of the present study}

The study was designed to estimate the incidence of pulmonary tuberculosis (PTB) disease among adolescents attending school in South India by using two different surveillance methods (active and passive).

\section{Methods}

\section{Study setting}

The study was conducted in the former Palamaner taluk of Chittoor District of Andhra Pradesh in South India approximately $135 \mathrm{~km}$ from Bangalore city from February 2007 to July 2010. The study area for this study consisted of 397 population units, of which 384 were rural. The estimated population at the time of the study was 250,000 [9]. The study area was chosen since the incidence of tuberculosis in this area is fairly similar to national rates in India, and the out-migration rate is low allowing for comprehensive follow-up.

\section{Study design}

The study was a prospective observational cohort study with a 2-year follow-up period.

\section{Sampling}

From an initial list of schools registered with the Government (Mandal) Education Office in the region, a random sampling procedure was used to select a subset of schools to enable approximately 8000 subjects to be available for randomization in the study. A stratified randomization procedure was used to assign the selected schools to either active or passive surveillance. Randomization for the public high schools was stratified by size of school, while the remaining schools were stratified by type of school (private high school, private junior college, or public junior college). The schools not selected during the initial random sampling procedure were also randomized using a similar stratified randomization procedure to either active or passive surveillance and were used only if the targeted number of subjects were not enrolled from the selected subset of schools.

\section{Study participants}

All adolescents aged $\geq 11$ to $<18$ years attending 58 high schools and four junior colleges (grades 7 through 12) in the study area were approached. The total number of eligible adolescents was 12,388. A decision to work in the schools was made to ensure the consistent conduct of this study and to minimize loss to follow-up.

Participants who indicated that they or their families were likely to move from the study area during the proposed 2 years of follow-up or who indicated that they were unable to attend the follow-up session for the tuberculin skin test (TST) reading at baseline were excluded from the study.

\section{Study procedures \\ Baseline assessment}

At baseline, all participants underwent the following procedures.

Questionnaires The parents or guardians were asked about the participant's clinical history, including BCG immunization status, history of current or past TB, history of close contact of more than $8 \mathrm{~h}$ a week with an adult with proven $\mathrm{TB}$, current signs or symptoms of $\mathrm{TB}$, and history of hospitalizations during the last 6 months and/or diagnosis of acute or chronic diseases. The adolescents were asked to review the medical history provided by their parents or guardians and to provide additional information, if any. Socio-demographic details and indicators were also recorded during the interview, including the parent's / guardian's occupation, education, 
and income; the subject's gender, religion, date of birth, and whether they were a member of a socially deprived community; and the type of walls found in the subject's home, type of cooking fuel used, and the presence or absence of a household electricity connection.

Clinical assessments The presence or absence of a BCG scar was noted. Height was measured to the closest $0.10 \mathrm{~cm}$ using a standard measuring tape with the subject standing against a wall in the Frankfurt plane; weight was recorded in school clothes but without footwear to the nearest $0.10 \mathrm{~kg}$ using a calibrated digital weighing scale (Bhaseen Health Product Pvt. Ltd., Jalandhar, India). Weight and height were used to compute Body Mass Index (BMI) and to derive the BMI-for-age $\mathrm{Z}$-scores as a measure of nutritional status. BMI for age Z-score was calculated using the Anthroplus software (Version 3.1, WHO, 2010). Based on the BMI for age Z-score, participants were classified as Underweight (BMI - Age Z-score less than or equal to -2), Overweight (BMI - Age Z-score greater than or equal to 1), or Normal (BMI - Age Z-score between -2 to 1; does not include -2 or 1 ) [10].

Tuberculin skin test Designated trained research nurses administered $0.10 \mathrm{ml}$ of tuberculin containing two TU Purified Protein Derivative (PPD) of RT 23 with Tween 80 as a stabilizer (SPAN Diagnostic Ltd, Surat, India) on the anterior surface of the forearm about two to four inches below the elbow. A designated trained tuberculin reader made the reading visit between 48 and $96 \mathrm{~h}$ after the skin test was administered. A wider window of 4 days for tuberculin skin test evaluation was used when the participant was unavailable for TST reading within $72 \mathrm{~h}$. Approximately $88 \%$ of participants were evaluated for the TST within 48 to $72 \mathrm{~h}$; the remaining participants were examined in the 4 day window. The skin test site was inspected in good light and the maximum transverse diameter of the induration was measured in millimetres using a transparent ruler calibrated in millimetres. The measurements were recorded and documented along with the date and time.

Blood sample All participants provided a $29 \mathrm{ml}$ blood sample, which was processed and stored for immunological analyses. Hemoglobin was estimated at the time of blood sampling using the Hemocue AB (HemoCue India, New Delhi, India).

Surveillance of participants A stratified randomisation procedure assigned the schools to either active or passive surveillance. Schools were chosen as the unit for randomisation, rather than individuals, to avoid contamination of follow-up type.
The participants in the active surveillance group were followed-up every 3 months and asked for any signs or symptoms of pulmonary $\mathrm{TB}$ and for any recent exposure to a known case of TB. A blood draw was also performed every 6 months. At the 1 year study visit, participants in the active surveillance group had a repeat TST.

The participants in the passive surveillance group were educated about symptoms related to pulmonary TB and asked to present to the diagnostic ward (DGW) if they developed symptoms and/or were exposed to a known case of tuberculosis.

In addition, all primary health care centres and hospitals in the study area, as well as major referral hospitals outside the study area, were visited once a week to determine whether any of the study participants had been diagnosed with PTB in the facility. To facilitate this process, all participants were given a study ID card, which indicated their enrolment into the study and included the study physician's contact details. The treating physicians at the health centres were requested to contact the study physician if they suspected PTB in the participant.

At the final study visit (Day 720), the baseline procedures were repeated among all participants in both the active and passive surveillance groups.

\section{Confirmation of TB}

TB confirmation The participant is diagnosed with pulmonary tuberculosis disease if the individual had (1) at least one positive culture result [Isolation of Mycobacterium tuberculosis (Mtb) from either one or both sputum samples using the GenoType MTBC test kit (HAIN kit)] or (2) one sputum smear result positive for acid fast bacilli (AFB) and positive polymerase chain reaction (PCR) for Mycobacterium tuberculosis or (3) two sputum smear results positive for $\mathrm{AFB}$, or (4) radiological evidence of PTB on a chest $x$-ray [Posterior-anterior (PA) view] with concurrent diagnosis by at least two radiologists.

If the participants had a recent history of positive TB contact, had symptoms suggestive of pulmonary TB (unexplained cough, unexplained fever, unexplained weight loss, unexplained night sweats for more than 2 weeks, and Haemoptysis), was diagnosed with pulmonary TB by any other physician, or had a positive TST (TST $\geq 10 \mathrm{~mm}$ ) during the baseline procedure or any of the follow-up visits, they were referred to the base hospital for further evaluation of PTB. On arrival to the base hospital, the participant's clinical history was reviewed and a clinical evaluation performed.

A chest $\mathrm{x}$-ray was taken at the hospital and read by one expert radiologist at St. John's Medical College. All $\mathrm{X}$-rays that were reported as abnormal and as possible PTB by the first radiologist were read independently by 
two additional radiologists at the same medical college. Sputum was collected on two consecutive days in a sterile container.

At the laboratory, the consistency of the sputum sample (i.e. salivary, mucoid, muco-purulent and blood stained) was noted. The sputum specimens were examined by concentrated AFB smear microscopy and processed for culture. The media used for the culture of Mycobacteria were Lowenstein-Jensen medium and Mycobacteria growth indicator tube (MGIT) medium. If a specimen was culturepositive, the species of the isolate was confirmed using the GenoType Mycobacterium CM kit and the GenoType MTBC kit (HAIN Lifescience, Germany). Participants who visited the DGW after the re-consent process had an additional $3 \mathrm{ml}$ blood drawn to assess immune response by an in vitro antigen stimulation test (QuantiFERON ${ }^{\circ}$-TB Gold In-Tube test) to identify M. tuberculosis infection. (Cellestis Limited, Australia, http://www.quantiferon.com/ IRM/content/default.aspx).

The final diagnosis and test results were communicated to the study participant's parent or guardian and medical care provider. If the sputum specimen was smear or culture-positive and/or if the chest $x$-ray was abnormal and suggestive of PTB, the results and participants were also reported to the government tuberculosis control program (Revised National Tuberculosis Control Programme - Directly observed short chemotherapy (RNTCP-DOTS)) for treatment.

\section{Case definitions}

If the participant had one sputum culture positive for Mtb [Isolation of Mtb from either one or both sputum samples using the GenoType MTBC test kit (HAIN kit)]; OR one AFB-positive sputum smear AND one positive PCR for Mtb; OR two AFB-positive sputum smears, they were considered to have a definite case of PTB. If the participant was not diagnosed as having definite TB but had a clinical assessment compatible with pulmonary TB and the chest X-ray was reported to be "abnormal and suggestive of TB" by at least two of the three radiologists, they were considered to have a probable case of PTB.

\section{Data management and analysis}

All data collected were entered into customized data acquisition software. All data forms were checked for missing data and clarity of data prior to data entry. Double data entry was done and disparities reconciled against the data forms. Descriptive statistics were reported using number and percentages. Total person years of follow-up were calculated. Incidence of TB with $95 \%$ confidence interval $(\mathrm{CI})$ in the active and passive surveillance groups was reported. Chi-square test was used to test the association between types of surveillance, whether the participant attended the DGW for TB screening, and re-consent status to other demographic and clinical characteristics of the subjects. P values less than $5 \%$ were considered statistically significant. All analyses were done using Statistical Package for Social Sciences Version 22.0 (SPSS, 22.0, SPSS Inc, Chicago, IL, USA).

\section{Results}

Of the 12,388 eligible adolescents approached, 3441 males and 3202 females were enrolled; response rates were 53 and $47 \%$ respectively. There were no differences in response rates observed between schools or in the response rates of males and females within a school. Among the 6643 subjects enrolled, 3102 (male 1728, female 1374) were followed in active surveillance and 3541 (male 1713, female 1828) were under passive surveillance. Of these adolescents, $59 \%(N=1841)$ were still in the study at the end of 2 years in the active surveillance group while $68 \%(N=1185)$ were still in the study at the end of 2 years in the passive surveillance group. A total of 1257 (male 698, female 559) and 1127 (male 527, female 600) subjects withdrew from the active and passive surveillance groups respectively. Of the 1257 adolescents who withdrew from the active surveillance group, approximately $2 / 3$ i.e. $68.74 \%(N=864)$ withdrew during the re-consenting process, which many participants found difficult to understand. The remaining $31.26 \%(N=393)$ withdrew for other various reasons. The majority of participants left the study area for education at other institutions, marriage, or with their families. A minority of subjects "felt sick (not TB symptoms) and did not want to continue in the study" $(N=3)$, "had examinations and withdrew from the study" $(N=2)$ and "were fasting during Ramzan (Ramadan) month and withdrew from the study" $(N=2)$. All 1127 adolescents in the passive surveillance group who withdrew from the study withdrew at the time of re-consent. There were six deaths reported: four (male 3, female 1) in the active group and two (male 1, female 1) in the passive group. Verbal autopsies were done for these participants; no cause of death was related to tuberculosis.

The baseline characteristics of the study subjects were published earlier [11, 12]. As per the parent's interview at baseline, out of the 6643 participants, 5674 had BCG immunization at birth and 843 participants had not received immunization. The data of the remaining 126 participants was not available. Figure 1 describes the complete study profile with all TB cases in our adolescent cohort. There were 1314 subjects who were referred to the DGW for the evaluation of pulmonary TB based on the criteria outlined earlier. Of these, 589 subjects attended the diagnostic ward. There were 29 subjects who attended the DGW as self-referrals. Of these 618 subjects screened for PTB, four subjects were diagnosed 


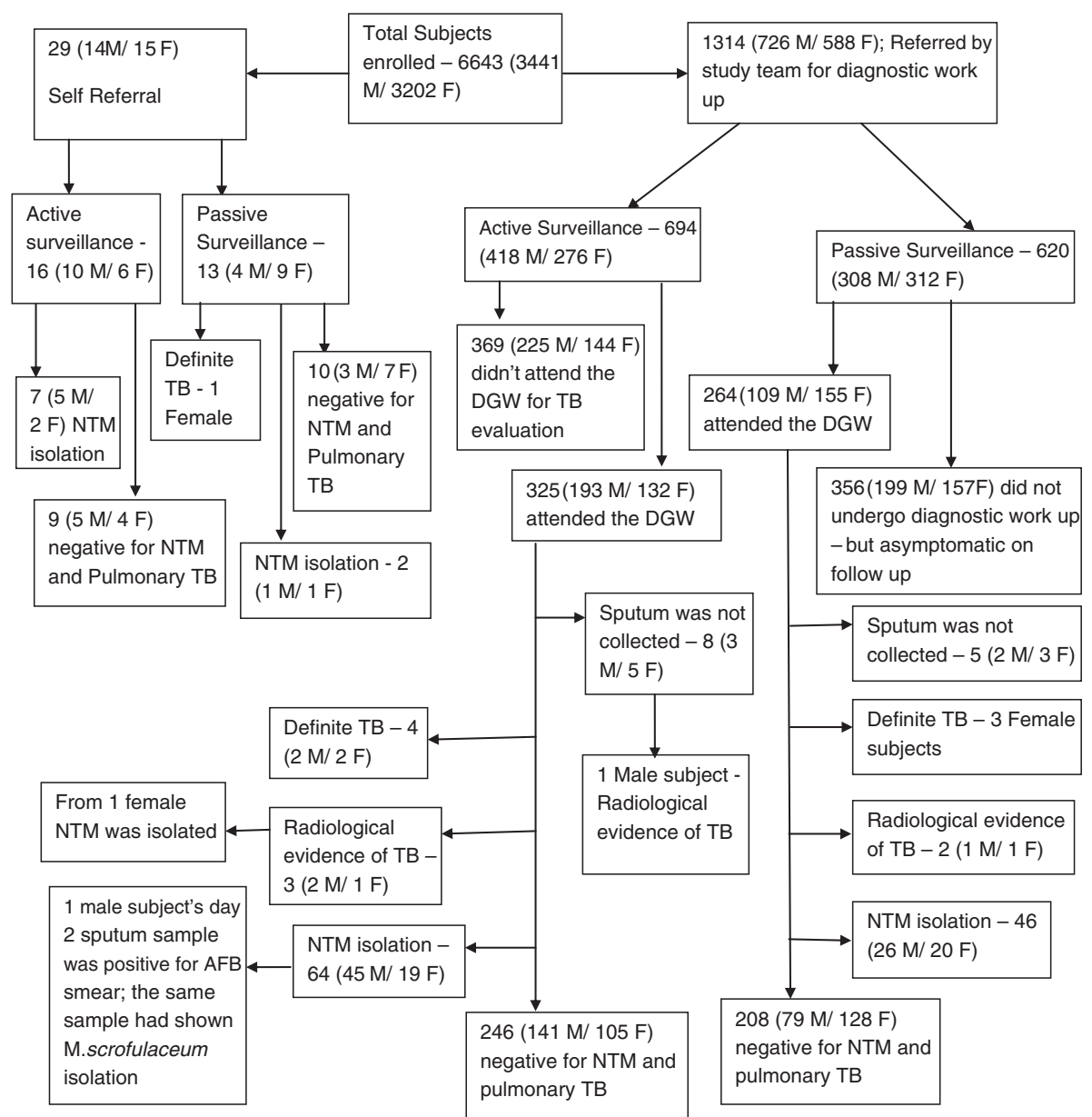

Fig. 1 Study profile and TB cases among the adolescent cohort

as having definite $\mathrm{TB}$, four subjects as having probable TB, and 71 subjects had Non-tuberculous Mycobacteria (NTM) isolated from their sputum in the active surveillance group. In the passive surveillance group, four subjects were diagnosed as having definite $\mathrm{TB}$, two subjects with having probable TB, and 48 subjects had NTM isolated from their sputum.

Table 1 describes different characteristics of the 14 definite and probable TB cases. One subject was diagnosed as having definite TB at his 3rd visit to the DGW, while all other subjects were diagnosed at their 1st visit to DGW. Of the eight culture positive cases, five were smear positive.

The total person years of follow-up in our study was 12,$350 ; 5419$ in the active surveillance group and 6931 in the passive surveillance group. The incidence of definite $\mathrm{TB}$, probable $\mathrm{TB}$, and definite + probable $\mathrm{TB}$ were 64.80 (95 \% CI: 30.10-123.00), 48.60 (95 \% CI: $19.70-$ 101.00), and 113.40 (95\% CI: 64.50-185.70) / 100,000 person years respectively in our study. The incidence of definite + probable TB was 147.60 (95 \% CI: 68.50-
180.30) / 100,000 person years in the active surveillance group and 87 (95 \% CI: 35.10-180.00) / 100,000 person years in the passive surveillance group.

Table 2 describes the subjects who attended the DGW for PTB evaluation in both the active and passive surveillance groups. The participants who attended the DGW in the active surveillance group were more likely to be older males with a recent history of weight loss and cough for more than 2 weeks compared to those in the passive surveillance group. The subjects who did not attend the DGW for PTB evaluation even after referral by the study team were more likely to be males, not to have subsequently given their re-consent, and were more likely to be negative for the TST during the follow-up compared to those subjects who attended the DGW for PTB evaluation after referral (Table 3).

Table 4 compares the subjects who re-consented to continue in the study following the change in study sponsors compared to those who withdrew from the study. The adolescents who withdrew were more likely to be 15-18 years age group and in the passive 
Table 1 Characteristic features of definite and probable TB cases

\begin{tabular}{|c|c|c|c|c|c|c|c|c|c|c|c|c|c|c|c|c|c|c|}
\hline \multirow[t]{2}{*}{ SI.No } & \multirow[t]{2}{*}{ Participant ID } & \multirow[t]{2}{*}{ Surveillance } & \multirow{2}{*}{$\begin{array}{l}\text { Visit } \\
(n)^{a}\end{array}$} & \multirow[t]{2}{*}{ Gender } & \multirow{2}{*}{$\begin{array}{l}\text { Age } \\
\text { (years) }\end{array}$} & \multirow[t]{2}{*}{$B A Z^{b}$} & \multirow[t]{2}{*}{ Smear $^{c}$} & \multirow[t]{2}{*}{ Culture $^{d}$} & \multicolumn{4}{|c|}{ Symptoms ${ }^{\mathrm{e}}$} & \multirow{2}{*}{$\begin{array}{l}\text { Past } \\
\text { TB }^{\mathrm{e}}\end{array}$} & \multirow{2}{*}{$\begin{array}{l}\mathrm{Hx} \text { TB } \\
\text { contact }^{\mathrm{e}, \mathrm{f}}\end{array}$} & \multirow{2}{*}{$\begin{array}{l}\text { Chest X Ray } \\
\text { reult } 9\end{array}$} & \multirow{2}{*}{$\begin{array}{l}\text { QFT } \\
\text { Result }^{\text {h }}\end{array}$} & \multirow{2}{*}{$\begin{array}{l}\text { TST Value } \\
(\mathrm{mm})^{\mathrm{i}}\end{array}$} & \multirow{2}{*}{$\begin{array}{l}\text { Person days } \\
\text { of follow up }\end{array}$} \\
\hline & & & & & & & & & Cough & Fever & Haemoptysis & Night sweats & & & & & & \\
\hline 1 & $12-104$ & Active & 3 & Male & 17 & Normal & $2 / 2$ & $2 / 2$ & + & - & - & - & - & + & $3 / 3$ & Positive & 16 & 706 \\
\hline 2 & 20-116 & Active & 1 & Female & 16 & $\begin{array}{l}\text { Under } \\
\text { weight }\end{array}$ & $2 / 2$ & $2 / 2$ & + & + & - & - & - & - & $3 / 3$ & NA & 15 & 472 \\
\hline 3 & $33-266$ & Active & 2 & Male & 15 & Normal & $2 / 2$ & $2 / 2$ & + & - & - & - & - & - & $3 / 3$ & Positive & 24 & 718 \\
\hline 4 & $42-107$ & Passive & 1 & Female & 12 & $\begin{array}{l}\text { Under } \\
\text { weight }\end{array}$ & $2 / 2$ & $2 / 2$ & + & - & + & - & - & - & $3 / 3$ & NA & 7 & 721 \\
\hline 5 & $72-601$ & Active & 1 & Female & 15 & $\begin{array}{l}\text { Under } \\
\text { weight }\end{array}$ & $2 / 2$ & $2 / 2$ & + & + & - & + & - & - & $3 / 3$ & Negative & 5 & 711 \\
\hline 6 & $23-061$ & Passive & 1 & Female & 17 & Normal & $0 / 2$ & $2 / 2$ & - & - & - & - & - & - & $0 / 3$ & Positive & 25 & 725 \\
\hline 7 & $52-301$ & Passive & 1 & Female & 15 & $\begin{array}{l}\text { Under } \\
\text { weight }\end{array}$ & $0 / 2$ & $1 / 2$ & - & - & - & - & - & - & $0 / 3$ & Positive & 17 & 725 \\
\hline 8 & $83-013$ & Passive & 1 & Female & 15 & $\begin{array}{l}\text { Under } \\
\text { weight }\end{array}$ & $0 / 2$ & $1 / 2$ & - & - & - & - & - & - & $0 / 3$ & NA & 23 & 706 \\
\hline 9 & $37-404$ & Active & 1 & Female & 15 & Normal & $0 / 2$ & $0 / 2$ & - & - & - & - & - & - & $3 / 3$ & Positive & 10 & 706 \\
\hline 10 & $37-430$ & Active & 1 & Male & 16 & Normal & $0 / 2$ & $0 / 2$ & - & - & - & - & - & + & $3 / 3$ & Positive & 19 & 732 \\
\hline 11 & $40-310$ & Passive & 1 & Male & 16 & $\begin{array}{l}\text { Under } \\
\text { weight }\end{array}$ & $0 / 2$ & $0 / 2$ & - & - & - & - & - & - & $3 / 3$ & NA & 18 & 706 \\
\hline 12 & $77-503$ & Active & 1 & Male & 14 & Normal & $0 / 2$ & $0 / 2$ & - & - & - & - & - & + & $3 / 3$ & NA & 20 & 729 \\
\hline 13 & $87-155$ & Passive & 1 & Female & 14 & Normal & $0 / 2$ & $0 / 2$ & - & - & - & - & - & - & $3 / 3$ & NA & 13 & 722 \\
\hline 14 & $26-101$ & Active & 1 & Male & 12 & Normal & & & - & - & - & - & - & - & $3 / 3$ & Positive & 22 & 710 \\
\hline
\end{tabular}

${ }^{a}$ The details in the table were corresponding to $\mathbf{n}^{\text {th }}$ visit of the participant

${ }^{b}$ BAZ body mass index for Age $Z$ - score; WHO cut offs 2007, Growth reference 5-19 years; calculated using WHO - ANTHRO software (version 3.2.2); Underweight $(<-2)$, Overweight $(>+1)$, Normal $(-2$ to +1$)$

c $2 / 2=$ two samples smears were positive for Acid fast bacilli of two samples, $1 / 2=$ one sample positive of two, $0 / 2=$ both samples were negative

$2 / 2=$ two samples smears were positive for Acid fast bacilli of two samples, $1 / 2=$ one sample positive of two, $0 / 2=$ both samples were negative
$2 / 2=$ two sputum samples had shown the isolation of Mycobacterium tuberculosis (M.tb) on Geno Type MTBC test kit (HAIN kit) of two samples; $1 / 2=$ one sample had M.tb of two; $0 / 2=$ both samples were negative

for M.tb

e Cumulative response of both parent and subject has been considered in case of
${ }^{f}$ Recent contact with a TB case at least for $8 \mathrm{~h}$ a week; in the period of 3 months

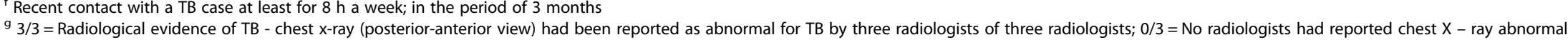

for TB

${ }^{\mathrm{h}}$ QFT quantiferon, $N A$ result Not available

' TST tuberculin skin test, the result value corresponds to the nearest one to the diagnostic ward (DGW) visit 
Table 2 Comparison of active/ passive surveillance group participants to the diagnostic ward in terms of baseline characteristics and other variables

\begin{tabular}{|c|c|c|c|}
\hline Variable & $\begin{array}{l}\text { Active surveillance } \\
(N=341)(\%)\end{array}$ & $\begin{array}{l}\text { Passive surveillance } \\
(N=277)(\%)\end{array}$ & $P$ value \\
\hline \multicolumn{4}{|l|}{ Gender } \\
\hline Male & $203(59.5)$ & $113(40.8)$ & \\
\hline Female & $138(40.5)$ & $164(59.2)$ & $<0.001$ \\
\hline \multicolumn{4}{|l|}{ Age } \\
\hline $12-13$ years & $38(11.1)$ & $33(11.9)$ & \\
\hline $14-15$ years & $171(50.1)$ & $163(58.8)$ & \\
\hline $16-17$ years & $87(25.5)$ & $72(26.0)$ & $<0.001$ \\
\hline $18-20$ years & $45(13.2)$ & $9(3.2)$ & \\
\hline \multicolumn{4}{|l|}{ Referral Reason } \\
\hline $\begin{array}{l}\text { Symptoms } \\
\text { suggestive of TB }\end{array}$ & $22(6.5)$ & $4(1.4)$ & 0.002 \\
\hline $\begin{array}{l}\text { Significant TB } \\
\text { exposure }\end{array}$ & $17(5.0)$ & $12(4.3)$ & 0.84 \\
\hline $\mathrm{TST} \geq 10 \mathrm{~mm}$ & $191(56.0)$ & $186(67.1)$ & 0.005 \\
\hline TST conversion & $69(20.2)$ & $54(19.5)$ & 0.84 \\
\hline $\begin{array}{l}\text { Symptoms and TST } \\
\text { conversion }\end{array}$ & $1(0.3)$ & $0(0.0)$ & N.A \\
\hline $\begin{array}{l}\text { Contact and TST } \geq \\
10 \mathrm{~mm}\end{array}$ & $2(0.6)$ & $0(0.0)$ & N.A \\
\hline $\begin{array}{l}\text { Symptoms and } \\
\text { TST } \geq 10 \mathrm{~mm}\end{array}$ & $8(2.3)$ & $2(0.7)$ & 0.19 \\
\hline $\begin{array}{l}\text { Symptoms and TB } \\
\text { contact }\end{array}$ & $2(0.6)$ & $0(0.0)$ & N.A \\
\hline Self-referral & $2(0.6)$ & $8(2.9)$ & 0.04 \\
\hline \multicolumn{4}{|l|}{ Weight loss $\geq 2$ weeks } \\
\hline Yes & $9(2.6)$ & $1(0.4)$ & \\
\hline No & $332(97.4)$ & 276 (99.6) & 0.02 \\
\hline \multicolumn{4}{|l|}{ Haemoptysis } \\
\hline Yes & $4(1.2)$ & $2(0.7)$ & \\
\hline No & $337(98.8)$ & $275(99.3)$ & 0.69 \\
\hline \multicolumn{4}{|l|}{ Cough $\geq 2$ weeks } \\
\hline Yes & $38(11.1)$ & $10(3.6)$ & \\
\hline No & $303(88.9)$ & $267(96.4)$ & $<0.001$ \\
\hline \multicolumn{4}{|l|}{ Fever $\geq 2$ weeks } \\
\hline Yes & $18(5.3)$ & $6(2.2)$ & \\
\hline No & $323(94.7)$ & $271(97.8)$ & 0.05 \\
\hline \multicolumn{4}{|l|}{$\begin{array}{l}\text { Night sweats } \geq \\
2 \text { weeks }\end{array}$} \\
\hline Yes & $6(1.8)$ & $1(0.4)$ & \\
\hline No & $335(98.2)$ & 276 (99.6) & 0.13 \\
\hline \multicolumn{4}{|l|}{$\begin{array}{l}\text { Subject diagnosed as } \\
\text { Pulmonary TB prior } \\
\text { to DGW visit }\end{array}$} \\
\hline Yes & $1(0.3)$ & $1(0.4)$ & \\
\hline No & 340 (99.7) & 276 (99.6) & 1.0 \\
\hline
\end{tabular}

Table 2 Comparison of active/ passive surveillance group participants to the diagnostic ward in terms of baseline characteristics and other variables (Continued)

\begin{tabular}{|c|c|c|c|}
\hline \multicolumn{4}{|l|}{$\begin{array}{l}\text { Significant TB } \\
\text { exposure }\end{array}$} \\
\hline Yes & $35(10.3)$ & $34(12.3)$ & \\
\hline No & $306(89.7)$ & $243(87.7)$ & 0.44 \\
\hline \multicolumn{4}{|l|}{ Caste } \\
\hline $\begin{array}{l}\text { Dalit/ Harijan (socially } \\
\text { disadvantaged } \\
\text { community) }\end{array}$ & 68 (19.9) & 44 (15.9) & \\
\hline Others & $273(80.1)$ & $233(84.1)$ & 0.20 \\
\hline \multicolumn{4}{|l|}{ Mother's education } \\
\hline Illiterate & $147(43.1)$ & $127(45.8)$ & \\
\hline $\begin{array}{l}\text { Primary education } \\
\text { or more }\end{array}$ & $193(56.6)$ & $149(53.8)$ & 0.51 \\
\hline \multicolumn{4}{|l|}{ Father's education } \\
\hline Illiterate & $82(24.0)$ & $78(28.2)$ & \\
\hline $\begin{array}{l}\text { Primary education } \\
\text { or more }\end{array}$ & $258(75.7)$ & $196(70.8)$ & 0.23 \\
\hline \multicolumn{4}{|l|}{ Type of house walls } \\
\hline Brick & $272(79.8)$ & $235(84.8)$ & \\
\hline Others & $69(20.2)$ & $42(15.2)$ & 0.11 \\
\hline \multicolumn{4}{|l|}{ Type of cooking fuel } \\
\hline Wood & $283(83.0)$ & $236(85.2)$ & \\
\hline Others & $58(17.0)$ & $41(14.8)$ & 0.14 \\
\hline \multicolumn{4}{|l|}{ Final Diagnosis } \\
\hline Definite TB & $4(1.2)$ & $4(1.4)$ & 1.0 \\
\hline $\begin{array}{l}\text { Radiological } \\
\text { evidence of TB }\end{array}$ & $4(1.2)$ & $2(0.7)$ & 0.69 \\
\hline NTM isolated & $71(20.8)$ & $48(17.3)$ & 0.30 \\
\hline $\begin{array}{l}\text { Negative for } \\
\text { Pulmonary TB }\end{array}$ & $254(74.5)$ & $217(78.3)$ & 0.29 \\
\hline
\end{tabular}

Missing data: Referral Reason-38 (6.1 \%), Mother's education-2 (0.3 \%), Father's education-4 (0.6 \%), Final Diagnosis-12 (1.9\%)

DGW diagnostic ward, TST tuberculin skin test, N.A not applicable, Referral reason - Referral criteria to the DGW; Symptoms suggestive of Pulmonary Tuberculosis (PTB) include Cough $\geq 2$ weeks, Fever $\geq 2$ weeks, Recent Weight loss for $\geq 2$ weeks, Night sweats $\geq 2$ weeks, Haemoptysis; Significant TB exposure - History of positive TB contact (for more than $8 \mathrm{~h} /$ week); Definite TB - Isolation of Mycobacterium tuberculosis from the either one or both sputum samples on GenoType MTBC test kit (HAIN kit); Radiological evidence of TB chest x-ray (posterior-anterior view) had been reported as abnormal for TB by at least two radiologists; NTM (Non-Tuberculous Mycobacteria) isolated from the either one or both sputum samples on GenoType Mycobacterium CM kit

surveillance group. They were also more likely to be negative for TST during the follow-up period, less likely to have symptoms suggestive of PTB, and were less likely to have significant TB exposure during the period under surveillance.

\section{Discussion}

In our study, the incidence density of definite and probable pulmonary $\mathrm{TB}$ among adolescents was 113 per 
Table 3 Comparison of responders/ non responders to the diagnostic ward in terms of baseline characteristics and other variables

\begin{tabular}{lll}
\hline Variable & $\begin{array}{l}\text { Attended DGW for } \\
\text { TB screening }\end{array}$ & Didn't attend \\
& the DGW (Non - & (Responders) \\
$(N=589)(\%)$ & Responders) \\
$(N=725)(\%)$
\end{tabular}

\begin{tabular}{llll}
\hline Gender & & & \\
Male & $302(51.3)$ & $424(58.5)$ & 0.01 \\
Female & $287(48.7)$ & $301(41.5)$ & \\
Age & & & \\
12 years & $175(29.7)$ & $170(23.4)$ & 0.08 \\
$13-14$ years & $296(50.3)$ & $391(53.9)$ & \\
$15-16$ years & $95(16.1)$ & $129(17.8)$ & \\
$17-18$ years & $23(3.9)$ & $35(4.8)$ &
\end{tabular}

Surveillance

$\begin{array}{llll}\text { Active } & 325(55.2) & 369(50.9) & 0.12 \\ \text { Passive } & 264(44.8) & 356(49.1) & \end{array}$

Caste

Dalit/ Harijan

(socially disadvantaged community)

Others

Mother's education

Illiterate
Primary education
or more

Father's education

Illiterate
Primary education
or more

Type of house walls

Brick
Others

Type of cooking fuel

Wood

$107(18.2)$

$150(20.7)$

Others

TST Positivity during 2 years of follow - up

Yes
No
Symptoms suggestive
of TB during the
2 years follow - up
Yes
No
Significant TB exposure
during the 2 years
follow - up
Yes

$97(16.5) \quad 96(13.2)$

$545(92.5) \quad 646(89.1)$

$44(7.5) \quad 79(10.9)$

Table 3 Comparison of responders/ non responders to the diagnostic ward in terms of baseline characteristics and other variables (Continued)

\begin{tabular}{|c|c|c|c|}
\hline No & 547 (92.9) & 690 (95.2) & \\
\hline \multicolumn{4}{|l|}{ Re - consent Status } \\
\hline Yes (Given) & $546(92.7)$ & $510(70.3)$ & $<0.01$ \\
\hline No (Not given) & $43(7.3)$ & $211(29.1)$ & \\
\hline \multicolumn{4}{|c|}{$\begin{array}{l}\text { Missing data: Mother's education - } 2 \text { (0.2 \%), Father's education - } 9(0.7 \%) \text {, Re } \\
\text { - consent status }-4(0.4 \%) \\
\text { a Does not include } 29 \text { participants who have attended the DGW without } \\
\text { referral during the follow-up } \\
D G W \text { diagnostic ward, TST tuberculin skin test, Symptoms suggestive of } \\
\text { Pulmonary Tuberculosis (PTB) include Cough } \geq 2 \text { weeks, Fever } \geq 2 \text { weeks, } \\
\text { Recent Weight loss for } \geq 2 \text { weeks, Night sweats } \geq 2 \text { weeks, Hemoptysis; } \\
\text { Significant TB exposure - History of positive TB contact (for more } \\
\text { than } 8 \mathrm{~h} / \text { week) }\end{array}$} \\
\hline
\end{tabular}

100,000 person years. The overall incidence of tuberculosis reported by WHO in India for all age groups was 170 per 100,000 person year population in 2012, which is greater than our study results [8]. A lower incidence might be expected in school-going adolescents than in the general population [8]. School-going children may also be healthier than their counterparts who drop-out of school due to socio-economic reasons. Data (2012-13) from the district in which this study was conducted indicate that the enrolment for students between standards I-V was $92 \%$, VI to VII $84 \%$, and VIII to X $75 \%$. The majority of our enrolments in the study were between standards VII and X [13]. School enrolment and drop-out rates vary across ages and gender [14]; being female and reasons related to poverty and economic reasons were major factors associated with drop-outs [15]. Thus, our study sample is likely to have had a smaller proportion of the very poor compared to the general population, which may be also the reason for lower incidence in our study.

In our study, the incidence of culture-positive PTB was 65 per 100,000 person years. Data in an earlier study conducted by the Tuberculosis Research Center, Chennai, Chingleput district, South India was 90 per 100,000 person year population among 10-24 year olds during the period of 1984-1986 [16]. The reduction in incidence may be attributed to a secular change in the incidence with the implementation of Revised National Tuberculosis Control Programme and the smaller age range of our study subjects. Similar studies in adolescents conducted in Eastern Uganda and South Africa show an overall incidence of 235 per 100,000 person years and 450 per 100,000 person years respectively $[17,18]$. However, these countries have a higher prevalence of TB in general, compared to India, and higher rates of human immunodeficiency virus (HIV). HIV status was not evaluated in our study population; however, data from the area indicate that the HIV prevalence among antenatal clinic attendees in Chittoor district between 2010 and 2011 was 0.50 to $1.00 \%$ and the 
Table 4 Comparison of those who re - consented to those who did not re - consent following a change in study sponsorship

\begin{tabular}{|c|c|c|c|}
\hline Variable & $\begin{array}{l}\text { Re }- \text { consent } \\
\text { given }^{a} \\
(N=4647)(\%)\end{array}$ & $\begin{array}{l}\text { Re }- \text { consent } \\
\text { was not given }{ }^{b, c} \\
(N=1937)(\%)\end{array}$ & $P$ value \\
\hline \multicolumn{4}{|l|}{ Gender } \\
\hline Male & $2427(52.2)$ & $978(50.5)$ & \multirow[t]{2}{*}{0.2} \\
\hline Female & $2220(47.8)$ & $959(49.5)$ & \\
\hline \multicolumn{4}{|l|}{ Age } \\
\hline 12 years & $1383(29.8)$ & $392(20.3)$ & \multirow[t]{4}{*}{$<0.01$} \\
\hline 13-14 years & $2453(52.8)$ & 1035 (53.4) & \\
\hline $15-16$ years & $675(14.5)$ & $415(21.4)$ & \\
\hline $17-18$ years & $136(2.9)$ & $95(4.9)$ & \\
\hline \multicolumn{4}{|l|}{ Surveillance } \\
\hline Active & $2235(48.1)$ & $808(41.7)$ & \multirow[t]{2}{*}{$<0.01$} \\
\hline Passive & $2412(51.9)$ & $1129(58.3)$ & \\
\hline \multicolumn{4}{|l|}{ Caste } \\
\hline $\begin{array}{l}\text { Dalit/ Harijan (socially } \\
\text { disadvantaged } \\
\text { community) }\end{array}$ & 878 (18.9) & $340(17.6)$ & \multirow[t]{2}{*}{0.2} \\
\hline Others & $3769(81.1)$ & $1597(82.4)$ & \\
\hline \multicolumn{4}{|l|}{ Mother's education } \\
\hline Illiterate & $2221(47.8)$ & $954(49.3)$ & \multirow[t]{2}{*}{0.3} \\
\hline $\begin{array}{l}\text { Primary education } \\
\text { or more }\end{array}$ & $2420(52.1)$ & $982(50.7)$ & \\
\hline \multicolumn{4}{|l|}{ Father's education } \\
\hline Illiterate & $1210(26.0)$ & $501(25.9)$ & \multirow[t]{2}{*}{0.86} \\
\hline $\begin{array}{l}\text { Primary education } \\
\text { or more }\end{array}$ & $3416(73.5)$ & $1430(73.8)$ & \\
\hline \multicolumn{4}{|l|}{ Type of house walls } \\
\hline Brick & $3674(79.1)$ & $1545(79.8)$ & \multirow[t]{2}{*}{0.52} \\
\hline Others & $973(20.9)$ & $392(20.2)$ & \\
\hline \multicolumn{4}{|l|}{ Type of cooking fuel } \\
\hline Wood & $3990(85.9)$ & $1653(85.3)$ & \multirow[t]{2}{*}{0.58} \\
\hline Others & $657(14.1)$ & $284(14.7)$ & \\
\hline \multicolumn{4}{|l|}{$\begin{array}{l}\text { TST Positivity during } \\
\text { the follow - up }\end{array}$} \\
\hline Yes & 949 (20.4) & $240(12.4)$ & \multirow[t]{2}{*}{$<0.01$} \\
\hline No & $3698(79.6)$ & 1697 (87.6) & \\
\hline \multicolumn{4}{|l|}{$\begin{array}{l}\text { Symptoms suggestive } \\
\text { of TB during the } \\
\text { follow - up }\end{array}$} \\
\hline Yes & $96(2.1)$ & $7(0.4)$ & \multirow[t]{2}{*}{$<0.01$} \\
\hline No & 4551(97.9) & 1930 (99.6) & \\
\hline \multicolumn{4}{|c|}{$\begin{array}{l}\text { Significant TB exposure } \\
\text { during the } 2 \text { years follow - up }\end{array}$} \\
\hline Yes & $65(1.4)$ & $12(0.6)$ & \multirow[t]{2}{*}{0.01} \\
\hline No & $4582(98.6)$ & $1925(99.4)$ & \\
\hline
\end{tabular}

Table 4 Comparison of those who re - consented to those who did not re - consent following a change in study sponsorship (Continued)

\begin{tabular}{llll}
\hline Referral to DGW Status & & & \\
Attended the DGW & $546(11.7)$ & $43(2.2)$ & $<0.01$ \\
$\begin{array}{l}\text { Didn't attend the DGW } \\
\text { even after referral }\end{array}$ & $510(11.0)$ & $211(10.9)$ & \\
$\begin{array}{l}\text { Visited DGW even } \\
\text { without referral } \\
\text { during follow - up }\end{array}$ & $25(0.5)$ & $4(0.2)$
\end{tabular}

Missing data: Mother's education - 7 (0.1\%), Father's education - $27(0.3 \%)$

${ }^{a}$ Among the 4647 adolescents one death was reported after re-consent process in active surveillance group which is also included in the table ${ }^{b}$ Fifty-nine subjects in active surveillance group whose day 720 form filled (closure of the study) before the re - consenting process data was considered as missing data. Of these three deaths were reported

c There were two deaths reported after re-consent process in the passive surveillance group whose number is included in the table

DGW diagnostic ward, TST - tuberculin skin test, Symptoms suggestive of Pulmonary Tuberculosis (PTB) include Cough $\geq 2$ weeks, Fever $\geq 2$ weeks, Recent Weight loss for $\geq 2$ weeks, Night sweats $\geq 2$ weeks, Haemoptysis; Significant TB exposure - History of positive TB contact (for more than $8 \mathrm{~h} /$ week)

prevalence of HIV in Andhra Pradesh state among adults was $0.90 \%$ [19].

Reliable epidemiological data on TB among adolescents is essential for accurate study design and planning for vaccine efficacy trials [20-22]. In India, the only available data among the adolescent age group, until now, is RNTCP data. Our study data aims to supplement the RNTCP data and to provide the additional details needed to conduct TB vaccine trials among adolescents in India.

The strengths of our study are the relatively large sample size, the detailed work up at baseline, the in-depth diagnostic evaluation, and the follow-up of participants in all clinics and hospitals within and surrounding the study area. The data available about response rates of schools at the time of enrolment into the study suggest that there is unlikely to be a responder bias; however, detailed health history was unavailable for the nonresponders to exclude this bias completely. The major limitation was the loss to follow-up that followed the change in the study sponsor that led to re-consenting subjects. Approximately $59 \%$ were still in the study at 2 years in the active surveillance group and $68 \%$ remained in the passive surveillance group. However, we do not believe that this loss to follow-up would have led to a decrease in the numbers of TB patients we detected, since weekly surveillance of clinics and hospitals within the study area and in the surrounding areas after the reconsent period did not reveal any new PTB cases from within our project area in the study age group. Another limitation was that only $44.80 \%$ of the patients referred to the diagnostic ward for screening actually underwent the procedures. However, we do not believe that this would have resulted in a significant underestimate of the 
incidence given that during follow-up in the field, the $55.20 \%$ of participants who did not undergo the diagnostic procedures did not worsen in health and did not attend any clinics or health centres under surveillance during the study. Indeed, the surveillance of the health centres was undertaken to particularly address the likelihood that participants might not be seen by the study physicians but might access other health providers in and around the study area. Fifty four participants who were suspected for TB and had symptoms suggestive of $\mathrm{TB}$ at the 2 year follow-up did not attend the diagnostic ward for TB diagnosis confirmation. These participants and others who did not attend the diagnostic ward were considered to not have TB in the analysis.

\section{Conclusion}

The incidence of pulmonary tuberculosis among adolescents in our study is much lower than similar studies conducted in South Africa and Eastern Uganda, which may be partly attributed to low incidence of HIV in India. The study data with higher incidence of PTB in active surveillance compared to passive surveillance method will help inform the design of future TB vaccine efficacy trials among adolescents in India.

\section{Abbreviations \\ ARTI, annual risk of tuberculosis infection; $A O R$, adjusted odds ratio; $B C G$, Bacillus Calmette Guerin; BMl, body mass index; Cl, confidence intervals; DOTS, directly observed short chemotherapy; DGW, diagnostic ward; HIV, human immunodeficiency virus; Mtb, mycobacterium tuberculosis; MGIT, mycobacteria growth indicator tube; MTBC, mycobacterium tuberculosis complex; NTMs, non-tuberculous mycobacteria; OR, odds ratio; PTB, pulmonary tuberculosis; RNTCP, revised national tuberculosis control programme; TST, tuberculin skin test; TU, tuberculin units; TB, tuberculosis; TBTSG, TB trials study group; WHO, World Health Organization}

\section{Acknowledgements}

The authors would like to thank the study team members at Palamaner and St. John's Research Institute for their invaluable contributions, and the community for their cooperation in the completion of this study; John Kenneth, formerly at St. John's Research Institute and Ragini Macaden who oversaw the diagnostic investigations in the field; R. Walker, L. Geiter, and Sean Bennett, formerly at the Aeras, USA; and the funding agencies, the Research Council of Norway (GLOBVAC:179342 and 192534 -through the Indo-Norway Programme; Indian partner-Department of Biotechnology) and the Aeras, USA.

The TB Trials Study Group (in alphabetic order)

1. Doherty TM, Vaccines, GlaxoSmithKline, Wavre, Belgium.

2. D'Souza G, Dept of Pulmonary Medicine, St. John's Medical College and St. John's Research Institute, Bangalore.

3. Grewal HMS, Department of Clinical Science, Infection, Faculty of Medicine and Dentistry, University of Bergen and Department of Microbiology,

Haukeland University Hospital, N-5021 Bergen, Norway.

4. Hesseling AC, Department of Pediatrics and Child Health, Desmond Tutu

TB Centre, Stellenbosch University, Cape Town, South Africa.

5. Jacob A, Emmaus Swiss Leprosy Project and Referral Hospital, Palamaner, Andhra Pradesh, India.

6. Jahnsen F, Department of Pathology, Oslo University Hospital,

Rikshospitalet and University of Oslo, Nydalen, Oslo, Norway.

7. Kurpad AV, Division of Nutrition, St. John's Research Institute, Bangalore, Karnataka, India.

8. Lau E, Aeras, Washington D.C., Metro Area, USA.

9. Lindtjorn B, Centre for International Health, Faculty of Medicine, University

of Bergen, Bergen, Norway.
10. Macaden R, Infectious Diseases, St. John's Research Institute, Bangalore, Karnataka, India.

11. Vaz M, Health and Humanities, St. John's Research Institute, Bangalore, Karnataka, India.

\section{Funding}

This work was partly supported by the Research Council of Norway through the Global Health and Vaccination Programme (GLOBVAC), project numbers 179342 and 192534, and partly by the Aeras, USA.

\section{Availability of data and material}

Data will not be shared. These data are part of a larger database from which multiple analyses are being performed across the tb trials study group.

\section{Authors' contributions}

Conceived and designed the experiments: DU, BL, HMSG, MV. Performed the experiments: DU, NJ, SS, HMSG, BL, MV. Analysed the data: DU, SS, BL, MV. Contributed reagents/ material/ analysis tools: SS, BL, MV. Wrote the manuscript: DU, BL, HMSG, MV. Reviewed the manuscript and provided critical comments: SS, ELL, TMD. Involved in the development of the protocol of the larger study within which the present analysis is embedded as well as the implementation and quality control of the study: TBTSG. Worked as medical officer for the project and was part of the clinical data collection and supervision: DU. Principal Investigators for the project: HMSG, MV. All authors read and approved the final manuscript.

\section{Competing interests}

The authors declare that they have no competing interests.

\section{Consent for publication}

Not applicable.

\section{Ethics approval and consent to participate}

Written informed assent from the subjects and consent from the parents or guardians were obtained at the time of enrolment before the start of study procedures. The study protocol and informed consent forms were reviewed and approved by the Institutional Review Board (IRB) of St. John's Medical College, Bangalore and by an Independent Ethics Committee (IEC) of the Aeras, Rockville, Maryland, USA. The studies were also approved by the Ministry of Health Screening Committee of the Government of India (No. 5/ 8/9/52/2006-ECD-I dt. 10.11.2006)

The study was stopped in September 2008 and restarted in November 2008 because of a change in study sponsors. When the study was restarted, reconsent was obtained from the participants.

\section{Author details}

'Department of Pharmacology, Rangaraya Medical College, Kakinada, Andhra Pradesh 533001, India. ${ }^{2}$ St. John's Research Institute, Bangalore, India. ${ }^{3}$ Formerly at St. John's Research Institute, Bangalore, India. ${ }^{4}$ Aeras, Metro Area, Washington, DC, USA. ${ }^{5}$ GSK Vaccines, Wavre, Belgium. ${ }^{6}$ Department of Clinical Science, Infection, Faculty of Medicine and Dentistry, University of Bergen, Bergen, Norway. ${ }^{7}$ Department of Microbiology, Haukeland University Hospital, N-5021 Bergen, Norway. ${ }^{8}$ Physiology and Head of Health and Humanities, St. John's Medical College, Bangalore, India. ${ }^{9}$ Centre for International Health, University of Bergen, Bergen, Norway.

Received: 10 November 2015 Accepted: 24 June 2016

Published online: 26 July 2016

References

1. GLOBAL TB REPORT - 2014 [http://www.who.int/tb/publications/global_ report/en/]

2. Glaziou P, Falzon D, Floyd K, Raviglione M. Global epidemiology of tuberculosis. Semin Respir Crit Care Med. 2013;34(1):3-16.

3. Lienhardt C, Glaziou P, Uplekar M, Lonnroth K, Getahun H, Raviglione M. Global tuberculosis control: lessons learnt and future prospects. Nat Rev Microbiol. 2012;10(6):407-16.

4. Cayabyab MJ, Macovei L, Campos-Neto A. Current and novel approaches to vaccine development against tuberculosis. Front Cell Infect Microbiol. 2012;2:154. 
5. Narayanan P. Influence of sex, age \& nontuberculous infection at intake on the efficacy of BCG: re-analysis of 15-year data from a double-blind randomized control trial in South India. Indian J Med Res. 2006;123(2):119.

6. Roy A, Eisenhut M, Harris RJ, Rodrigues LC, Sridhar S, Habermann S, Snell L, Mangtani P, Adetifa I, Lalvani A, et al. Effect of BCG vaccination against Mycobacterium tuberculosis infection in children: systematic review and meta-analysis. BMJ. 2014;349:g4643.

7. Comstock GW, Livesay VT, Woolpert SF. The prognosis of a positive tuberculin reaction in childhood and adolescence. Am J Epidemiol. 1974; 99(2):131-8.

8. Global tuberculosis report 2012. [http://www.who.int/tb/publications/ global_report/en/]

9. District C. Census 2001 data. New Delhi: Office of The Registrar General and Census Commissioner, India; 2007.

10. Growth reference 5-19 years: BMl-for-age (5-19 years). [http://www.who.int/ growthref/tools/en/]

11. Murthy M, Selvam S, Jesuraj N, Bennett S, Doherty M, Grewal HM, Vaz M, Group TTS. Two-step tuberculin skin testing in school-going adolescents with initial 0-4 $\mathrm{mm}$ responses in a high tuberculosis prevalence setting in South India. PLoS One. 2013;8(9), e71470.

12. Uppada DR, Selvam S, Jesuraj N, Bennett $S$, Verver $S$, Grewal HM, Vaz M. The tuberculin skin test in school going adolescents in South India: associations of socio-demographic and clinical characteristics with TST positivity and non-response. BMC Infect Dis. 2014;14(1):571.

13. Sarva Shiksha A, editor. Education, DoE, Govt. Of Andhra Pradesh. Hyderabad: Department of Education, Govt. Of Andhra Pradesh; 2014

14. Kumar TV. Post Enumeration Survey of DISE 2011 (5\% sample check). Hydearbad: Centre for Equity and Social Development; National Institute Of Rural Development; 2012.

15. Reddy AN, Sinha S. School Dropouts or Pushouts? Overcoming Barriers for the Right to Education. CREATE Pathways to Access. Research Monograph No. 40. 2010.

16. Radhakrishna S, Frieden TR, Subramani R, Kumaran PP. Trends in the prevalence and incidence of tuberculosis in south India. Int J Tuberc Lung Dis. 2001:5(2):142-57.

17. Waako J, Verver S, Wajja A, Ssengooba W, Joloba ML, Colebunders R, Musoke P, Mayanja-Kizza H. Burden of tuberculosis disease among adolescents in a rural cohort in Eastern Uganda. BMC Infect Dis. 2013;13:349.

18. Mahomed H, Ehrlich R, Hawkridge T, Hatherill M, Geiter L, Kafaar F, Abrahams DA, Mulenga $\mathrm{H}$, Tameris M, Geldenhuys $\mathrm{H}$, et al. TB incidence in an adolescent cohort in South Africa. PLoS One. 2013;8(3), e59652.

19. National AIDS Control Programme Phase III; State Fact Sheets. [http://www. aidsdatahub.org/national-aids-control-programme-phase-iii-state-fact-sheetsnational-aids-control-organisation-india-2012]

20. Brennan MJ, Thole J. Tuberculosis vaccines: a strategic blueprint for the next decade. Tuberculosis. 2012;92 Suppl 1:S6-13.

21. Brennan MJ, Fruth U, Milstien J, Tiernan R, de Andrade Nishioka S, Chocarro L. Development of new tuberculosis vaccines: a global perspective on regulatory issues. PLoS Med. 2007;4(8), e252.

22. Hawkridge T, Mahomed H. Prospects for a new, safer and more effective TB vaccine. Paediatr Respir Rev. 2011;12(1):46-51.

\section{Submit your next manuscript to BioMed Central and we will help you at every step:}

- We accept pre-submission inquiries

- Our selector tool helps you to find the most relevant journal

- We provide round the clock customer support

- Convenient online submission

- Thorough peer review

- Inclusion in PubMed and all major indexing services

- Maximum visibility for your research

Submit your manuscript at www.biomedcentral.com/submit
Biomed Central 